\title{
Research on the displacement change of construction enclosure system of deep foundation
}

\author{
Fei LIU ${ }^{1, *}$, Mingliang $\mathrm{SHNE}^{2}$, Hongmei $\mathrm{WANG}^{3}$ \\ ${ }^{1}$ Shanghai Urban Construction Vocational College, College of Civil and Traffic Engineering, Shanghai, P.R. China \\ ${ }^{2}$ Shanghai Construction Group, General contractor department, Shanghai, P.R. China \\ ${ }^{3}$ Shanghai Urban Construction Vocational College, College of Civil and Traffic Engineering, Shanghai, P.R. China
}

\begin{abstract}
By analyzing the monitoring data of the excavation of foundation, the maximum lateral displacement depth and the top vertical displacement of the retaining wall, the vertical displacement of the column are studied. Research indicates that the 3rd power polynomial curve can better fit the depth change law of the maximum lateral deformation of retaining wall at each monitoring point; the fourth support demolition has great influence on the lateral displacement and deformation of retaining wall. The excavation of the third layer has greatly increased the deformation of the top of retaining wall. After the second support is removed, the vertical deformation of the top of the retaining wall change to negative. The vertical deformation of the column gradually decreases until the deformation becomes smooth after the first support is removed. The deep excavation should be paid attention to the monitoring of the internal displacement and the upward displacement of the retaining wall, the vertical displacement of the column from the excavation of the third layer to the removal of the fourth support.
\end{abstract}

\section{Introduction}

With the continuous excavation of group and deep foundation in Shanghai, the importance of deformation monitoring has become increasingly prominent. The excavation of the foundation will affect the surface uplift of the pit and present a "groove shape" ${ }^{[1]}$; the combination of "two walls " and basin excavation can be used for deep foundation pit maintenance and cultural relic protection ${ }^{[2]}$; "dual-purpose pile" support system can save space greatly ${ }^{[3]}$; using FLAC 3D to calculate the influence of the deep foundation pit ${ }^{[4]}$.

The monitoring of the displacement of the retaining wall and the vertical displacement of the column directly reflect the safety of foundation excavation. Takes the deep excavation in the Xiao dong men area of Shanghai as the research object in this paper. Based on the monitoring data of the whole process of the excavation, the excavation process is used as the research time axis to analyze the displacement of the retaining wall and column. The study results of the change law of the excavation enclosure system in riverfront of Shanghai and the design of depth of foundation pit support will guide construction and feedback design.

\section{Engineering situation}

The project is located in the Xiao dong men block of Huang pu District that is the central and riverfront of
Shanghai. A typical riverside soft soil sediment in this district. The project is divided into 18 foundation pits with a maximum depth of $23.6 \mathrm{~m}$. The foundation pit studied in this paper is a normal excavation method. The depth of the foundation pit is $18.5 \mathrm{~m}$ and the area of the foundation is $9947 \mathrm{~m}^{2}$. It is setted with $1000 \mathrm{~mm}$ thick diaphragm wall and four concrete supports to make sure the safety. The monitoring period in this area was 640 days, and a total of 414 times were conducted.

\section{Monitoring and analysis of retaining wall displacement}

Pre-embedded $\Phi 70 \mathrm{~mm}$ PVC pipe in the retaining wall to monitor the lateral displacement of the retaining wall. The depth of PVC pipes are the same as the length of the retaining wall. The PVC pipes are setted with two sets of $90^{\circ}$ longitudinal guide to control the test orientation. Test with an inclinometer. The vertical displacement of the top of retaining wall is monitored by the embedded settlement mark on the top of the wall.

Analyzing the lateral displacement data of different monitoring points at different depths, it is found that the lateral displacement of the retaining wall gradually increases with the change of depth, and reaches a peak between the fourth support and the bottom layer, and then the lateral displacement of the retaining wall gradually decreases until it exceeds the range of influence. Through the monitoring results of the lateral displacement of the retaining wall, the maximum lateral displacement depth of each monitoring point of CX4-3-CX4-11 can be obtained

\footnotetext{
* Corresponding author: liufei@succ.edu.cn
} 
as $17 \mathrm{~m}, 15.5 \mathrm{~m}, 15.5 \mathrm{~m}, 16 \mathrm{~m}, 17 \mathrm{~m}, 17 \mathrm{~m}, 15 \mathrm{~m}, 14 \mathrm{~m}$. Therefore, the maximum deformation depth of each monitoring point is selected to study the change of the foundation pit construction process(as shown in Figure 1).

It can be seen from Fig. 1 that the lateral displacements of different monitoring points at the maximum lateral displacement of the retaining wall gradually increase with the construction process and move towards to the construction area. During the period from the completion of the pouring bottom layer to remove the third support, the lateral deformation of the retaining wall had a rapidly increase, and than change to increase slowly. This change law indicating that the removal of the fourth support had a great impact on the deformation of the lateral displacement of the retaining wall. The removal of the third to the first support will not cause major changes in the lateral displacement of the retaining wall. Therefore, the deformation monitoring of the retaining wall during the removal of the fourth support should be strengthened.

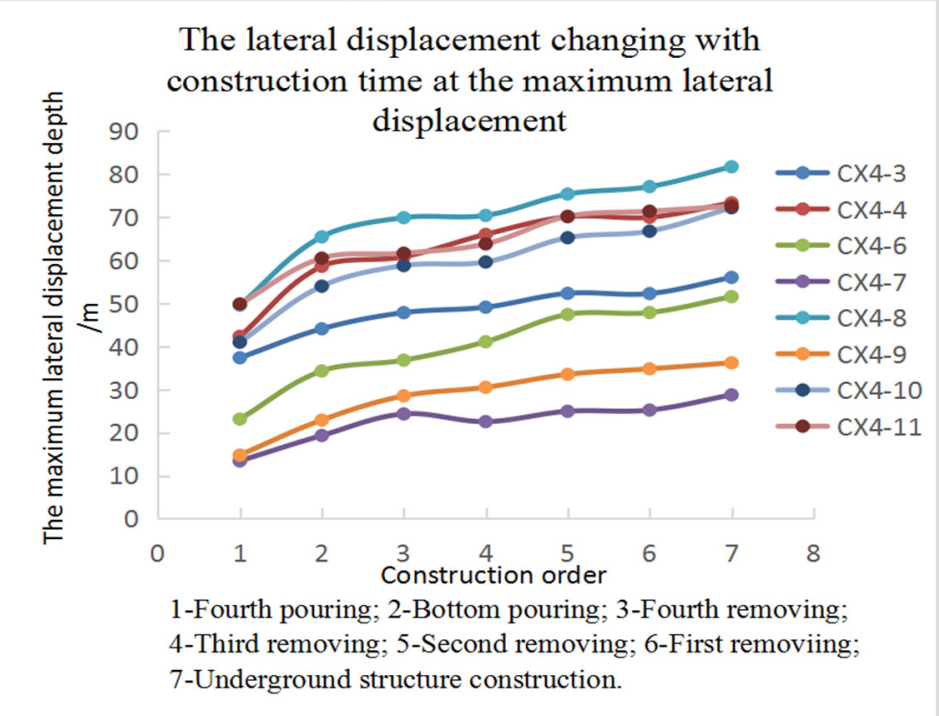

Fig 1. The law of lateral displacement changing with construction time at the maximum lateral displacement.

In order to further study the variation law of the maximum lateral displacement of the retaining wall with the construction process, the average value of the maximum lateral displacement depth of the monitoring points at different stages of the construction process are used for regular research and curve fitting (as shown in Fig.2).

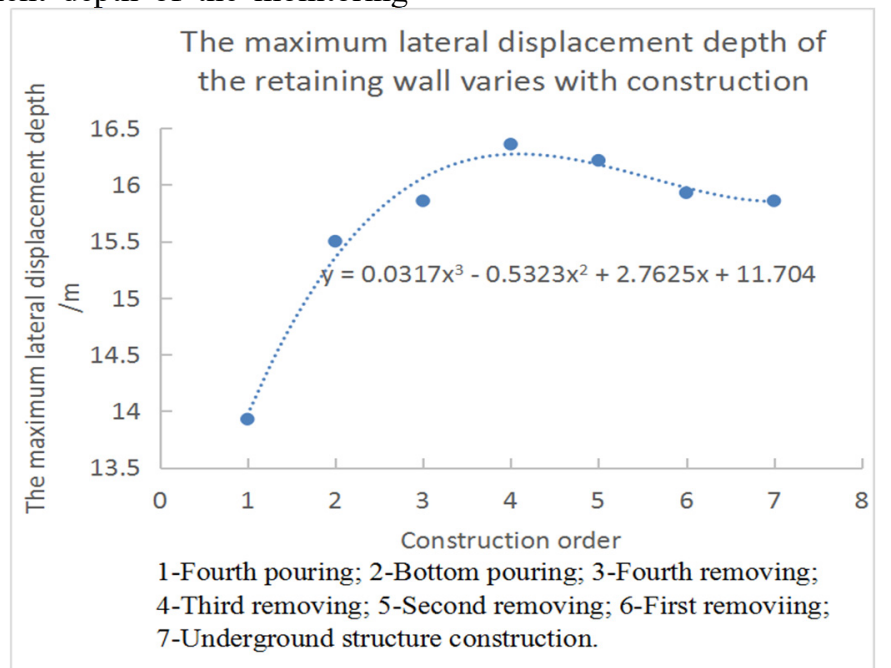

Fig 2. Curve fitting of the average value of the maximum lateral deformation depth of the retaining wall at each onitoring point.

The change law of each point in average value of the maximum lateral displacement depth of the retaining wall during different construction periods are showed in Fig.2. The analyzed results showed that the third-order polynomial curve can better fit the maximum lateral deformation depth of the retaining wall at each monitoring point. The maximum lateral displacement depth is appears between the fourth support and the bottom layer. Before the fourth support is removed, the maximum lateral deformation depth of the retaining wall gradually deepens as the construction progresses, and the growth rate gradually increases. After the completion of the construction of the fourth support, the maximum lateral deformation depth of the retaining wall decreased until the construction of the underground structure of the plot began, and the maximum lateral deformation of the retaining wall gradually tends to $16 \mathrm{~m}$ that the original fourth support.

This result shows that the depths where the maximum 
lateral displacement of the retaining are between the fourth support and the bottom layer. Deformation monitoring and optimization of construction methods should be strengthened to reduce the lateral displacement of the retaining wall.

From Figure 3, the vertical displacement change law of the top of the retaining wall during different construction periods shows that the top of the retaining wall is rising during the excavation of the foundation pit. Before the second layer is excavated and poured, the vertical deformation of the top of the retaining wall is relatively slow. When the third layer is excavated, the deformation of the top of the retaining wall increases significantly until the fourth layer is completed. The vertical deformation begins to decrease slowly.

At the end of the pouring of the bottom slab and from gradual removal of the fourth to third supports, the vertical deformation of the top of the retaining wall decreases rapidly; when the second support is removed, the vertical deformation of the top of the retaining wall is negative. That means the top of the retaining wall begins to deform downward. This pattern of change shows that the vertical displacement of the retaining wall during the excavation process of the foundation pit is rise, and the maximum vertical displacement reaches $20 \mathrm{~mm}$; when the bottom plate is poured and the support is gradually removed, the upward trend gradually decreases. After the second support is removed, it gradually showed a downward trend.

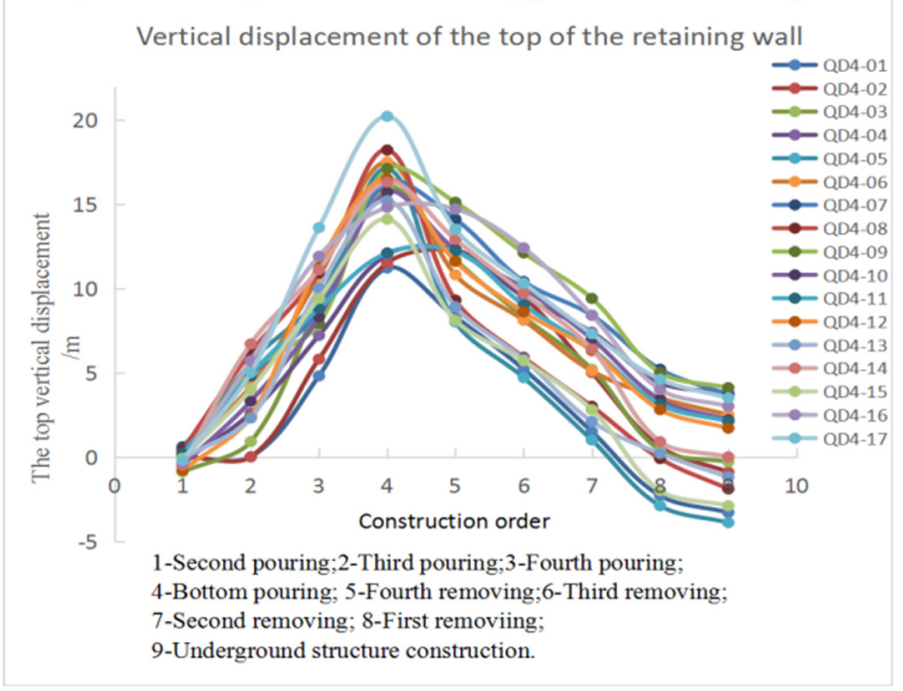

Fig 3. Vertical displacement of the top of the retaining wall.

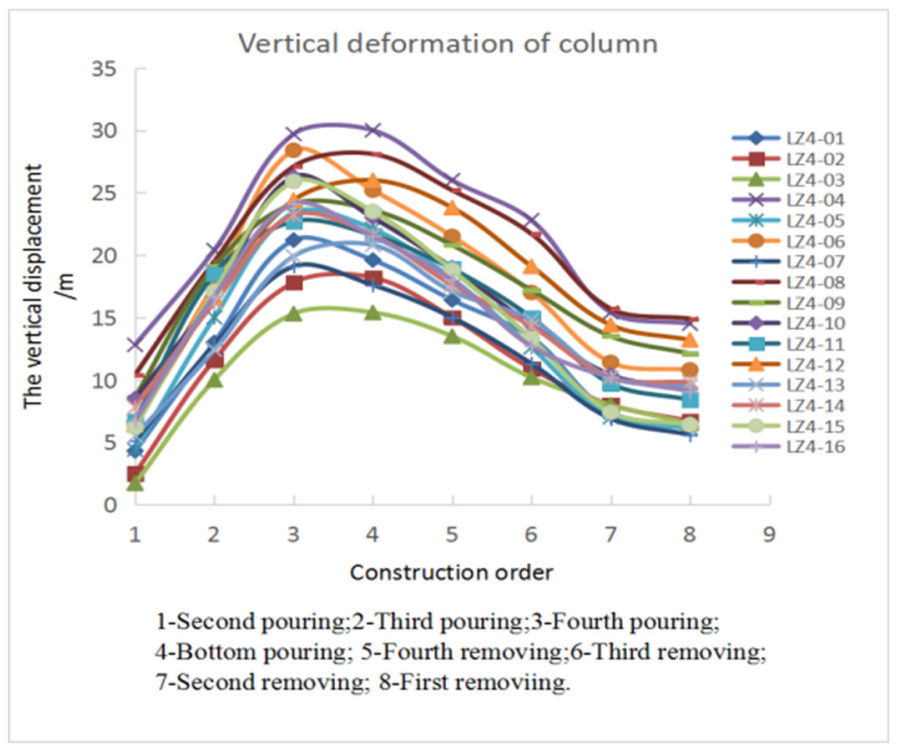

Fig 4. Vertical deformation of column.

\section{Column displacement monitoring and analysis}

During the excavation of the foundation pit, the elevation change at the top of the column can be monitored to grasp the rebound amount of the supporting column after a large amount of soil in the excavation pit is unloaded, which provides useful information for the safety analysis of the supporting system. Settlement nails are embedded at the top of the column piles to monitor the vertical displacement in study area.

From the vertical displacement curve of the monitoring points of each column in Figure 4, it is known that with the continuous construction of the foundation pit, the monitoring points of each column finally appear to rise, 
and the peak value reaches $30 \mathrm{~mm}$. The vertical deformation of the column changes rapidly from the excavation of the second layer to the completion of bottom pouring; from the excavation of the third layer to the completion of pouring fourth layer, the growth rate of the vertical deformation of the column is reduced. The maximum vertical deformation is reached $30 \mathrm{~m}$ when the fourth layer pouring was finished. With the gradual removal of the support, the vertical deformation of the column gradually decreases. Until the first support is removed, the deformation of the most monitoring points of the column tends to be smooth.

\section{Conclusion}

Through the study of the maximum lateral displacement and the top vertical displacement of the retaining wall,the vertical displacement of the column, the change law are as follows:

1.The 3rd power polynomial curve can better fit the depth change law of the maximum lateral deformation of retaining wall at each monitoring point. The maximum lateral displacement of retaining wall appears between the fourth support and the bottom plate; the fourth support remove has a greater impact on the deformation of the lateral displacement of the retaining wall.

2. The excavation of the third layer has greatly increases the deformation of the top of retaining wall. The deformation of the top of the retaining wall will reduce slowly until the fourth layer was excavated and poured. After the second support is removed, the vertical deformation of the top of the retaining wall change to negative, which means that the top of the retaining wall begins to deform downward.

3. The monitoring points of each column showed up lift and reached the maximum vertical deformation of $30 \mathrm{~mm}$ in the end when the fourth layer pouring was completed. With the gradual removal of the support, the vertical deformation of the column gradually decreases until the deformation becomes smooth after the first support is removed.

4. We should pay attention to the displacement from the excavation of the third layer to the removal of the fourth support.

\section{References}

1. Yang Ke. Deformation characteristics and control measures of each process in the deep excavation in Shanghai soft soil. Building Structure. 46, 732-736 (2016)

2. DI Guo-en, HUANG Bing-de, WANG Wei-dong. Design and application of the deep excavation in sensitive environment. Chinese Journal of Geotechnical Engineering. 32, 383-387(2010)

3. ZHOU Yong, ZHU Qiaohong, ZHU Yanpeng. The fourth support demolition has great influence on the lateral displacement and deformation of retaining wall. Chinese Journal of Rock Mechanics and Engineering. 39, 3168-3177(2020).
4. ZHANG Ming, YAN Liang, PAN Chu-wei. Influence of deep foundation pit excavation on safety of adjacent subway station. Journal of Civil Engineering and Management. 37, 99-104(2020). 